\title{
Atrioventricular groove patch plasty for anatomically corrected malposition of the great arteries
}

Kiyozo Morita, MD

Hiromi Kurosawa, MD

Katsushi Koyanagi, MD

Koji Nomura, MD

Yoshimasa Uno, MD

Hirokuni Naganuma, MD

Yoko Matsumura, MD

Takahiro Inoue, MD

From the Department of Cardiovascular Surgery, Jikei University School of Medicine, Tokyo, Japan.

Received for publication June 21, 2000; revisions requested July 31, 2000; revisions received Jan 29, 2001; accepted for publication March 28, 2001.

Address for reprints: Hiromi Kurosawa, MD, 3-25-8 Nishi-shinbashi Minatoku, Tokyo 105-8461, Japan (E-mail: kurosawa@jikei.co.jp).

J Thorac Cardiovasc Surg 2001;122:872-8

Copyright (C) 2001 by The American Association for Thoracic Surgery

0022-5223/2001 $\$ 35.00+0 \quad$ 12/1/116204

doi:10.1067/mtc.2001.116204
Objective: In anatomically corrected malposition of the great arteries, dextroposition of the posterior pulmonary artery and levoposition of the anterior aorta are associated with the leftward deviation of the proximal portion of the right coronary artery away from the right atrioventricular groove. This anatomic feature allows a transannular subpulmonary patch plasty of the right ventricular outflow tract along the right atrioventricular groove between the right coronary artery and the tricuspid anterior anulus (ie, atrioventricular groove patch plasty) for relief of subpulmonary stenosis without jeopardizing the right coronary artery.

Methods: This report describes the midterm results of a new surgical technique, atrioventricular groove patch plasty with a monocuspid transannular patch for subpulmonary stenosis, in 3 patients with anatomically corrected malposition of the great arteries, along with a concomitant closure of ventricular septal defects.

Results: Postoperative catheterization revealed adequate relief of pulmonary stenosis, with a pressure gradient of $8.0 \pm 3.5 \mathrm{~mm} \mathrm{Hg}$ and with normalized right ventricular pressure $(33 \pm 10 \mathrm{~mm} \mathrm{Hg})$, contributing to excellent midterm results with no late death and reoperation during a postoperative follow-up period of $70 \pm 47$ months.

Conclusion: This technique provides a promising alternative to Rastelli-type conduit repair for subpulmonary stenosis in anatomically corrected malposition of the great arteries.

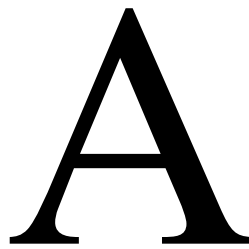

natomically corrected malposition of the great arteries (ACMGA) is a rare entity of conotruncal malformation in which the aorta and pulmonary artery arise from their appropriate ventricles, despite the presence of malposition of the great arteries. ${ }^{1}$ When the atrioventricular connection is concordant, the circulation is physiologically normal (concordant ACMGA), and surgical repair should consist of correction of associated lesions. ${ }^{1,2}$

The infundibular stenosis associated with ACMGA has been noted to be difficult to relieve because of the course of the right coronary artery (RCA) in front of the posterior pulmonary trunk, which may preclude a transannular patch repair. $^{2}$ However, the conotruncal malformation in concordant ACMGA $\{\mathrm{S}, \mathrm{D}, \mathrm{L}\}$, which is characterized by dextroposition of the posterior pulmonary artery and levoposition of the anterior aorta in the setting of complete transposition of the great arteries $\{\mathrm{S}, \mathrm{D}, \mathrm{D}\},{ }^{3}$ is associated with the leftward shift of the RCA away from the right atrioventricular groove. Furthermore, there is a poste- 

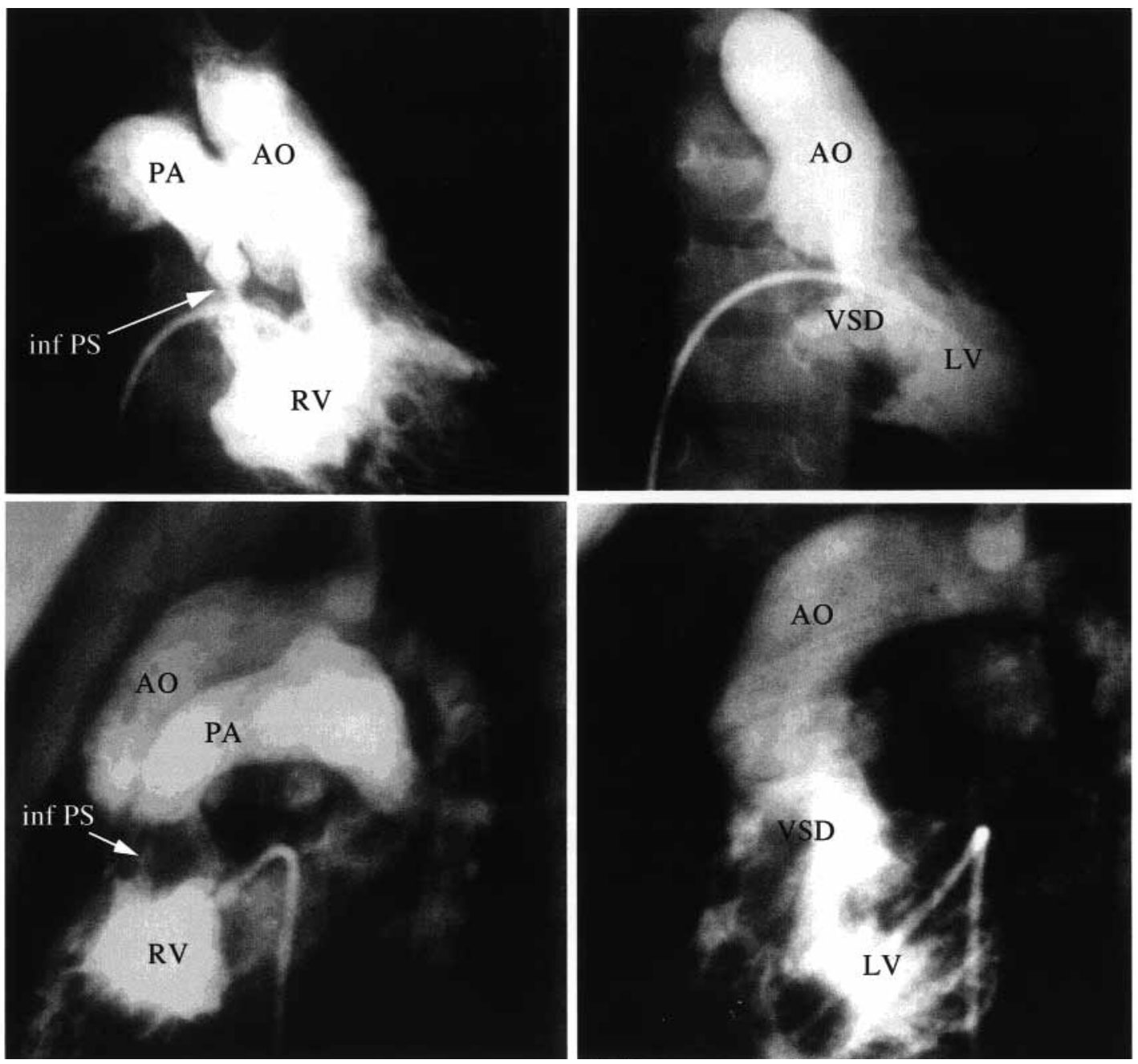

Figure 1. Preoperative cineangiogram in the morphologically right ventricle (left panels) and in the morphologically left ventricle (right panels) in patient 3. The morphologically right ventricle (RV) was positioned to the right of the morphologically left ventricle (LV) and gave rise to the pulmonary artery (PA), whereas the aorta (AO) arose from the left-sided morphologically left ventricle. The aorta was to the anterior and to the left of the pulmonary trunk (L-malposition). inf PS, Infundibular pulmonary stenosis.

rior atrioventricular conduction bundle as a result of concordant atrioventricular relation. This anatomic feature allows a transannular subpulmonary incision of the right ventricular outflow tract along the right atrioventricular groove between the RCA and the tricuspid anulus for relief of subpulmonary stenosis without jeopardizing both the RCA and regular posterior atrioventricular conduction bundle.

This report describes the midterm results of a new surgical technique, atrioventricular groove patch plasty with a monocuspid transannular patch, 4,5 for subpulmonary stenosis in 3 patients (age range, 2-12 years) with ACMGA $\{\mathrm{S}, \mathrm{D}, \mathrm{L}\}$, along with a concomitant closure of ventricular septal defects (VSDs).

\section{Methods \\ Patients}

Three patients were given a diagnosis of concordant ACMGA $\{\mathrm{S}, \mathrm{D}, \mathrm{L}\}$ with perimembranous outlet-type VSD and subpulmonary-valvular pulmonary stenosis, as determined by using preoperative cineangiography (Figure 1). The left juxtaposition of the atrial appendages and well-developed bilateral ventriculoinfundibular fold (VIF) were also identified in all patients. The most common type of coronary branching pattern in complete transposition, ${ }^{6}$ in which the RCA arises from the right facing sinus and the left coronary artery originates from the left facing sinus, was seen in patients 2 and 3 . The single coronary artery from the right facing sinus was noted in patient 1 .

Patient 1 also had muscular VSD, tricuspid stenosis, and a hypoplastic right ventricle, with the right ventricular end-diastolic 

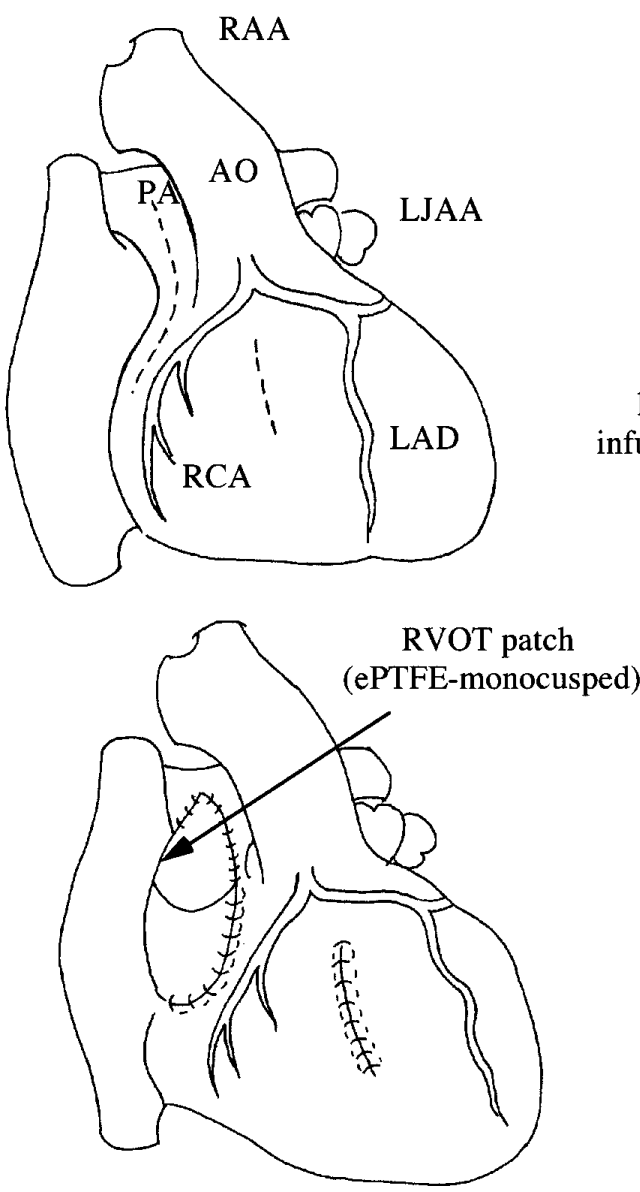
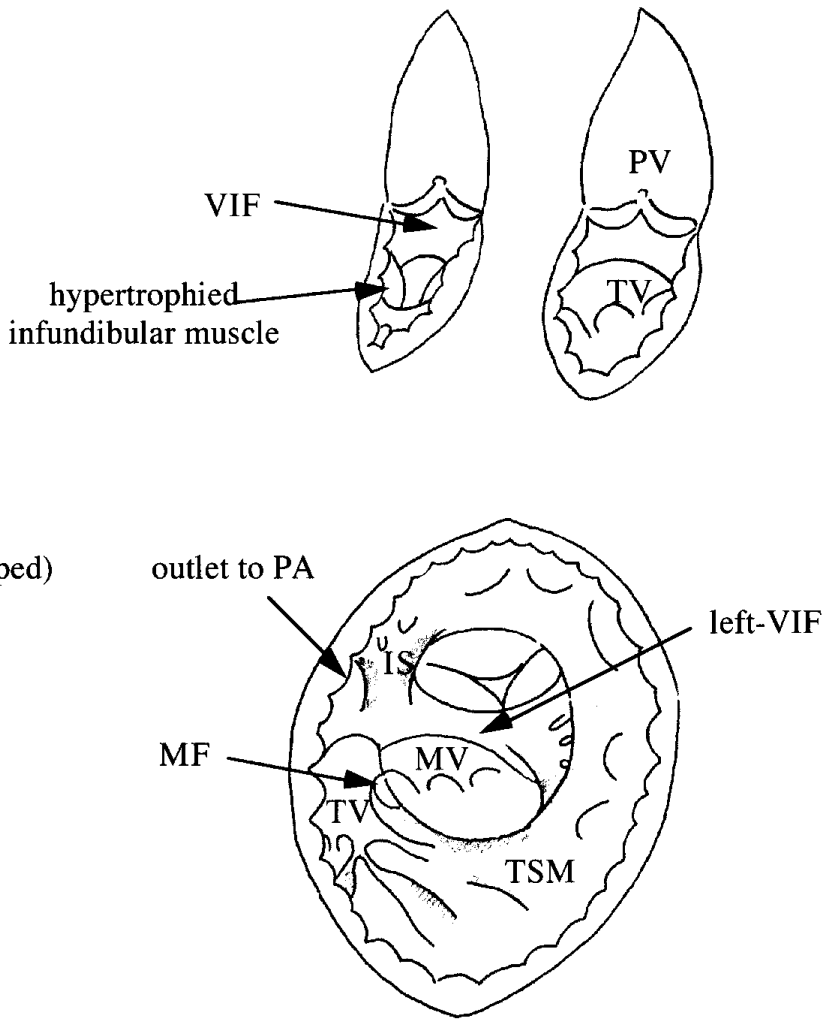

Figure 2. Surgical anatomy and procedures (patient 1). Gross anatomy was typical ACMGA $\{S, D, L\}$ with right aortic arch (RAA) and left juxtaposition of atrial appendages (LJAA). The RCA was displaced toward the apex away from the right atrioventricular groove. A pulmonary incision was extended into the right ventricular outflow tract (RVOT) between the RCA and the tricuspid anulus along the right atrioventricular groove. IS, Infundibular septum; $T S M$, trabecula septomarginalis; $P V$, pulmonary valve; $T V$, tricuspid valve; $M V$, mitral valve; $M F$, membranous flap.

\section{TABLE 1. Preoperative catheterization data}

\begin{tabular}{lccccccc}
\hline Patient & Age $(\mathbf{y})$ & RVP $(\mathbf{m m} \mathbf{H g})$ & PAP $(\mathbf{m m} \mathbf{~ H g})$ & RVP/LVP ratio & 0p/0s & LVEDV (\%) & RVEDV (\%) \\
\hline 1 & 10 & $95 / 0$ & $22 / 13(17)$ & 0.92 & 0.76 & 126 \\
2 & 12 & $82 / 0$ & $42 / 5(15)$ & 0.7 & 1.79 & 130 & 89 \\
3 & 2 & $92 / 0$ & $11 / 8(10)$ & 0.92 & 0.66 & 66 & 72 \\
\hline
\end{tabular}

$R V P$, Right ventricular pressure; $P A P$, pulmonary arterial pressure; $Q p / Q s$, pulmonary/systemic flow ratio; $L V E D V$ and $R V E D V$, left and right ventricular enddiastolic volume, respectively (percentage of normal expected values).

volume index being $52 \%$ of normally expected values (determined by the method of Simpson). Patient 2 required a redo operation because of residual VSD shunt and incomplete relief of pulmonary stenosis 6 years after the initial intracardiac repair (pulmonary valvotomy with closure of perimembranous VSD). Age at the time of operation and preoperative hemodynamic data are shown in Table 1.

\section{Operative Procedures}

PATIENT 1. At operation, external inspection of the heart confirmed the angiographic findings of ACMGA $\{\mathrm{S}, \mathrm{D}, \mathrm{L}\}$ (Figure 2). The $\mathrm{RCA}$ originating from the left anterior descending coronary artery obliquely crossed the right ventricular outflow tract but was displaced in a left anterior fashion away from the right atrioventricular groove. The distance between the displaced RCA and the atrio- 


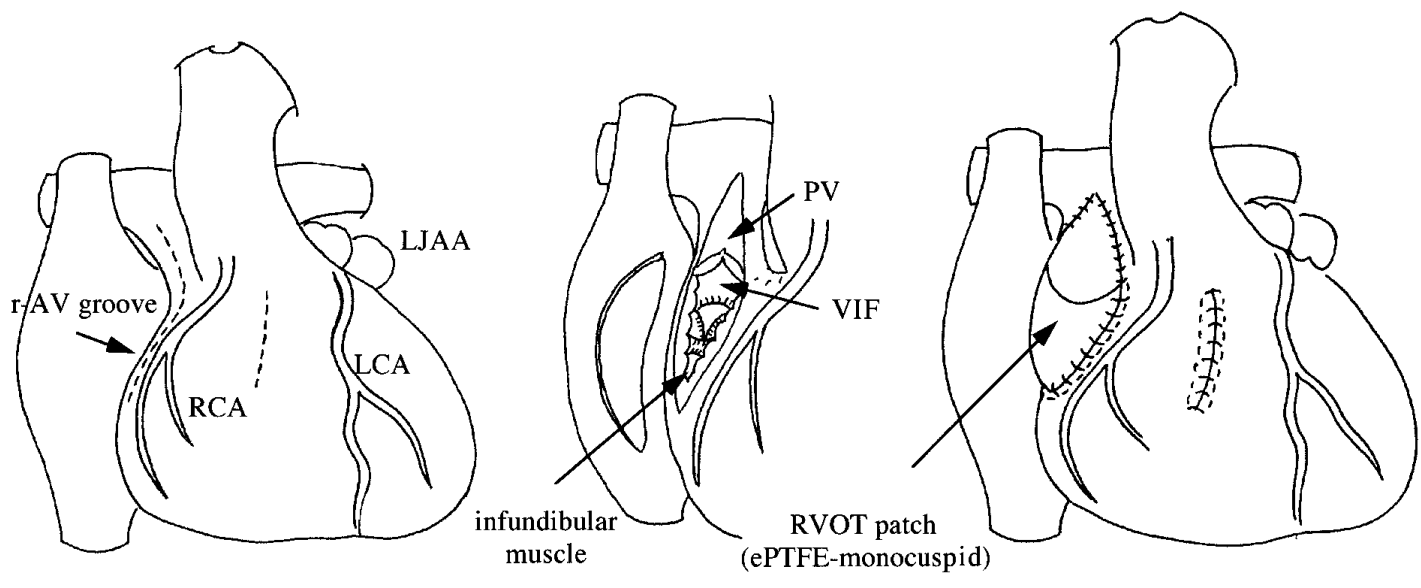

Figure 3. Surgical procedures in patient 3. The RCA obliquely crossed the right ventricular outflow tract (RVOT) beneath the pulmonary trunk and gradually reached the right atrioventricular $(r-A V)$ groove thereafter. Careful dissection of the right atrioventricular groove with transatrial identification of the tricuspid anulus enabled a longitudinal incision in the right ventricular outflow tract between the RCA and tricuspid anulus.

ventricular groove was approximately $7 \mathrm{~mm}$ on an epicardial surface. A longitudinal incision in the main pulmonary artery was extended into the right ventricular outflow tract along the right atrioventricular groove between the RCA and the tricuspid anulus. The outflow tract was reconstructed by placing an expanded polytetrafluoroethylene (e-PTFE) monocuspid bovine pericardial patch after resection of hypertrophied infundibular muscles. Another longitudinal right ventriculotomy was performed to allow exposure of a perimembranous VSD. The lower margin was formed by mitral-tricuspid fibrous continuity, with a membranous flap as seen in tetralogy of Fallot. ${ }^{4}$ There was well-developed VIF between the aortic valve and the mitral valve. There was an unusually prominent trabeculation in the left ventricular outflow tract formed by the displaced anterior limb of trabecula septomarginalis that was fused to the left-sided VIF, resulting in subaortic muscular infundibulum. The VSD was closed with a bovine pericardial patch and interrupted 5-0 mattress sutures. An intraoperatively identified additional VSD located in the muscular trabecular portion was also closed with direct sutures reinforced with a Dacron felt strip.

PATIENT 2. The leftward displacement of the proximal portion of the RCA from the right atrioventricular groove was also noted, and the distance between the RCA and the atrioventricular groove was comparable with that in patient 1 . An incision was made in the previous patch in the pulmonary trunk and extended to the right ventricular outflow between the RCA and the tricuspid anulus. Infundibular hypertrophied muscle was extensively resected, and an e-PTFE monocuspid bovine patch was sutured to augment the right ventricular outflow tract. The left pulmonary artery stenosis was also repaired with a bovine pericardial patch. The leakage of VSD patch was closed with 4 pledget-supported mattress sutures through the incision of the ascending aorta.

PATIENT 3. The surgical procedures used in patient 3 are illustrated in Figure 3. The RCA obliquely crossed the right ventricular outflow tract beneath the pulmonary trunk and gradually reached the right atrioventricular groove thereafter. The distance between the proximal portion of the RCA and the right atrioven- tricular groove was 2 to $3 \mathrm{~mm}$, which was shorter than that in the other 2 patients. Therefore, transannular incision into the right ventricular outflow tract appeared not to be a practical option, as previously described. Nevertheless, careful dissection of the right atrioventricular groove could identify the sufficient width of a portion of the right ventricular outflow tract between the tricuspid anulus and the RCA. These maneuvers enabled a transannular subpulmonary incision of the right ventricular outflow tract along the right atrioventricular groove, as in patients 1 and 2 . The outflow tract was reconstructed by placing an e-PTFE monocuspid bovine pericardial transannular patch after resection of hypertrophied infundibular muscles. Perimembranous outlet VSD was closed with a bovine pericardial patch and interrupted 5-0 mattress sutures.

\section{Results}

The postoperative courses were uneventful, with no evidence of arrhythmia and heart failure in any of the 3 patients. There was neither surgical nor late death. Postoperative catheterization carried out $12 \pm 3$ months after the operation demonstrated no residual shunt and sufficient relief of pulmonary stenosis (right ventricular pressure, $33 \pm$ $10 \mathrm{~mm} \mathrm{Hg}$; right ventricular/left ventricular pressure ratio, $0.33 \pm 0.09$; systolic pressure gradient across the right ventricular outflow, $8.0 \pm 3.5 \mathrm{~mm} \mathrm{Hg}$ ). Postoperative cineangiography in the morphologically right ventricle and the morphologically left ventricle of patient 3 is shown in Figure 4. Echocardiographic examination performed $62 \pm$ 45 months after the operation revealed nonrestricted motion of the PTFE monocusp without significant pulmonary regurgitation in all 3 patients, and trivial tricuspid regurgitation was noted only in patient 3 . At the time of last followup, $70 \pm 47$ months postoperatively, all patients were in excellent clinical condition and in sinus rhythm (Table 2). 

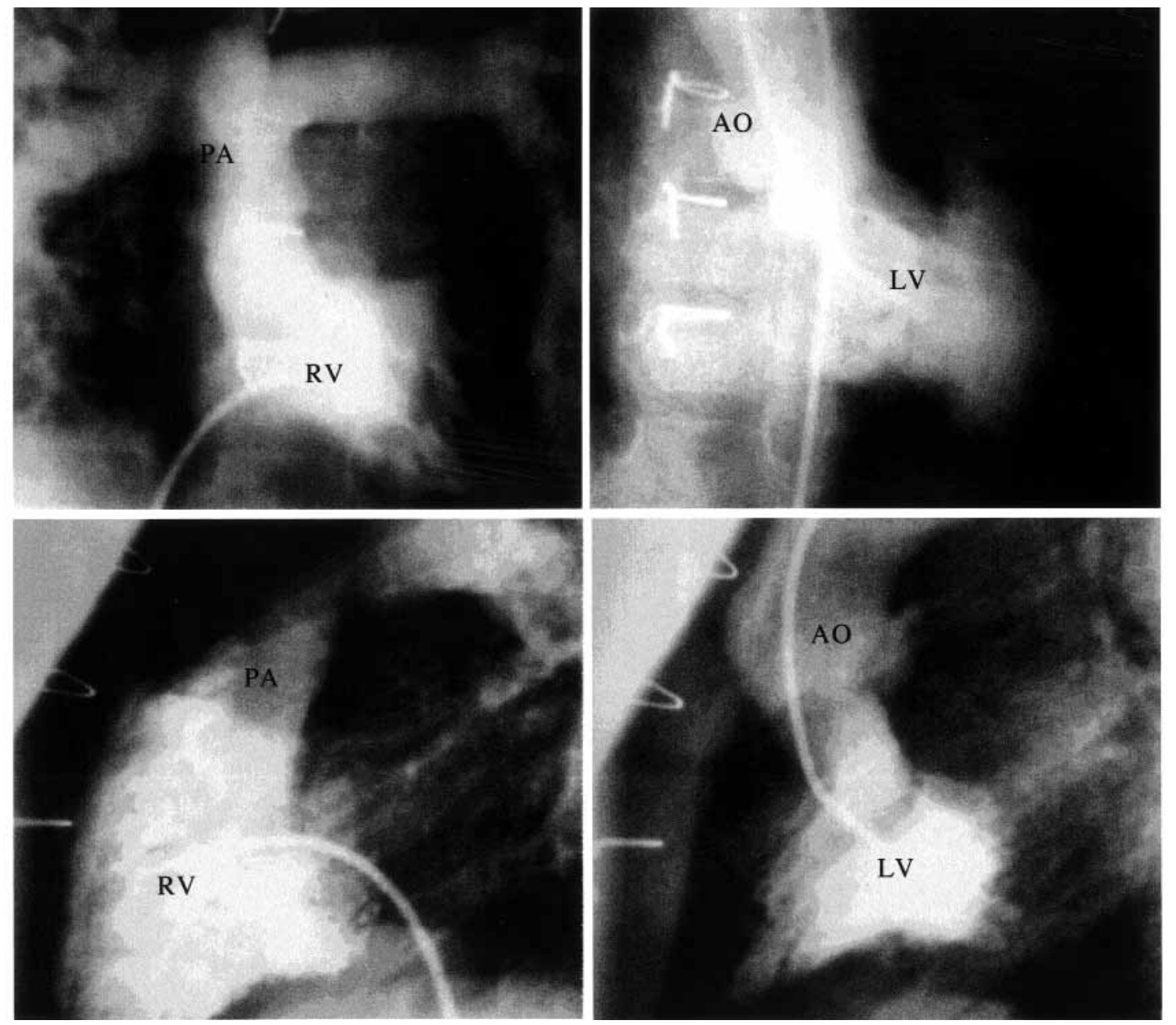

Figure 4. Postoperative cineangiogram in the morphologically right ventricle ( $R V$, left panels) and in the morphologically left ventricle ( $L V$, right pane/s) in patient 3 . There was no evidence of residual shunt and right ventricular outflow tract stenosis. AO, Aorta.

\section{Discussion}

Anderson and associates ${ }^{1}$ described ACMGA as a condition in which the great arteries arise in an unusual fashion from their morphologically appropriate ventricles, emphasizing that this entity describes not a discrete anomaly but only a ventriculoarterial relation. This relation is one of ventriculoarterial concordant connection and can coexist with all varieties of atrioventricular relations: S,D,L; I,L,D; S,L,D; and I,D,L. All patients in this report belonged to the S,D,L subgroup, which is the most common among patients described thus far. ${ }^{7,8}$ Morphologic findings observed in our patients, including bilateral VIF, left juxtaposition of atrial appendages, right aortic arch, anomaly of the coronary artery distribution pattern, and prominent trabeculation of the left ventricular outflow tract, which forms the anterior subaortic infundibulum together with left VIF, are consistent with those previously described as ACMGA in the literature. ${ }^{1,7,9}$ Anterior subaortic infundibulum, which results from a levoposition of the anterior aorta, allows the anterior great artery to arise from the left ventricle.

Valvular or subvalvular pulmonary stenosis is a frequently associated condition and has been reported in more than half of the patients who underwent the operation. ${ }^{2}$ Pulmonary valvotomy or infundibular muscle resection has been performed in the majority of reported patients with ACMGA, but it has resulted in incomplete relief of subpulmonary stenosis in some patients $2,9,10$ and required a conversion to the Rastellitype conduit repair, as reported by Rittenhouse and associates. ${ }^{2}$ The extracardiac conduit repair, however, raises the unsolved issue of long-term durability of the conduit and morbidity. ${ }^{11}$ Furthermore, a transannular patch has been thought not to be a practical solution because of the epicardial course of the RCA in front of the pulmonary artery. Lincoln and colleagues ${ }^{12}$ inserted a patch beneath the RCA to enlarge the subpulmonary outflow tract. 
TABLE 2. Surgical outcome

\begin{tabular}{lcccccc}
\hline & \multicolumn{3}{c}{ Postoperative hemodynamic data } & & Outcome & Follow-up \\
\cline { 2 - 5 } Patient & RAP (mm Hg) & RVP (mm Hg) & RVP/LVP ratio & PS (mm Hg) & & Alive and well \\
1 & $13 / 0(6)$ & $25 / 0(\mathrm{e} 5)$ & 0.23 & 4 & & Alive and well \\
2 & $12 / 4(7)$ & $45 / 0(\mathrm{e} 10)$ & 0.33 & 10 & & $113 \mathrm{mo}$ \\
3 & $7 / 2(5)$ & $30 / 0(\mathrm{e} 18)$ & 0.42 & 10 & Alive and well & $20 \mathrm{mo}$ \\
\hline
\end{tabular}

$R A P$, Right atrial pressure; $R V P$, right ventricular pressure; $P S$, systolic pressure gradient across right ventricular outflow tract.

The present study documents the feasibility of transannular patch repair in this type of conotruncal anomaly, unlike in transposition of the great arteries (D-transposition or L-transposition), because of its unique morphologic features. In all of our patients, there was leftward deviation of the RCA away from the right atrioventricular groove associated with a levoposition of the anterior aorta. A transannular subpulmonary incision of the right ventricular outflow tract along the right atrioventriclar groove was successfully performed to relieve subpulmonary stenosis without jeopardizing the main trunk of the RCA. The outflow tract was reconstructed by placing a PTFE monocuspid bovine pericardial patch, which is a standard procedure for tetralogy of Fallot in our institute because of the excellent long-term durability of the PTFE monocusp. ${ }^{4}$

Although the incision along the right atrioventricular groove may divide some atrial branches of the RCA, supraventricular arrhythmia, including sinus node dysfunction, was not seen postoperatively in all patients. However, if the major atrial branch of the RCA, especially the artery supplying the sinus node, is present across the right atrioventricular groove, this procedure should be adopted with caution.

The principal morphologic features of ACMGA $\{$ S,D,L $\}$ is a levoposition of the anterior aorta associated with dextroposition of the posterior pulmonary artery (ie, conotruncal criss-cross) in the setting of complete transposition of the great arteries $\{\mathrm{S}, \mathrm{D}, \mathrm{D}\} .^{3}$ As regards the morphogenesis of this anomaly, Goor and Edwards ${ }^{13}$ suggested that ACMGA may result from "isolated conal inversion," which implies inversion of conal musculature together with the arteries in reverse direction to that normally seen. Another possible explanation is plugging in of the aorta and the pulmonary artery in reverse or "isolated truncal inversion." 12 Anderson and colleagues ${ }^{1}$ documented that ACMGA could result from conal maldevelopment together with truncal inversion, which is similar to the concept of conotruncal criss-cross. Regardless of the true morphogenesis, the leftward deviation of the RCA associated with the levopositioned anterior aorta and dextropositioned posterior pulmonary artery can be interpreted as the anatomically reasonable consequence of conotruncal criss-cross and therefore might be seen casually in typical ACMGA and other malformations with S,D,L-type conotruncal anomaly.

The concept of transannular patch repair by using the morphologic advantages of ACMGA was first presented by Kurosawa in the Tokyo Symposium on Pediatric Cardiology and Pediatric Cardiac Surgery (Cardiology in the Young Symposium) held in Tokyo on October 30, 1995, and the operative procedure was introduced in the video series. Subsequently, his concept has recently been applied to double-outlet right ventricle with L-malposition $\{\mathrm{S}, \mathrm{D}, \mathrm{L}\} .{ }^{14}$ The feasibility of this method in the various malformations with S,D,L-type conotruncal anomaly may depend on the degree of levoposition of the anterior aorta and dextroposition of the posterior pulmonary trunk, as well as the pattern of epicardial course of the RCA.

Another common associated lesion of ACMGA is VSD. The VSD is often a perimembranous outlet of a malalignment type. The tricuspid and mitral valves are somewhat in continuity in the posterior edge of the defect, and the roof of the defect is formed by a relatively long infundibular septum, resulting in unusual configuration, such as an anterior subarterial infundibulum in the left ventricle. Our patients had these typical characteristics of VSD in ACMGA, resembling that in original TaussigBing anatomy. Furthermore, as seen in patient 1, additional muscular VSD has been reported ${ }^{3,4}$ and should not be overlooked. The normally positioned posterior conduction bundle has been found in concordant ACMGA, ${ }^{1}$ as in transposition of the great arteries, with a perimembranous or muscular outlet VSD, and in that case a conventional technique to avoid damage to the conduction bandle can be safely used.

The present report describes the excellent midterm results of atrioventricular groove patch plasty for subpulmonary stenosis in ACMGA with a monocuspid transannular patch by using morphologic advantages of this type of conotruncal malformation. This technique provides a promising alternative to Rastelli-type conduit repair for subpulmonary stenosis in ACMGA and similar conotrucnal malformations belonging to same spectrum. 


\section{References}

1. Anderson RH, Becker AE, Losekoot TG, Gerlis LM. Anatomically corrected malposition of great arteries. Br Heart J. 1975;37:9931013.

2. Rittenhouse EA, Tenckhoff L, Kawabori I, Mansfield PB, Hall DG, Brown JW. Surgical repair of anatomically corrected malposition of the great arteries. Ann Thorac Surg. 1986;42:220-8.

3. Kurosawa H, Van Mierop. Surgical anatomy of the infundibular septum in transposition of the great arteries with ventricular septal defect. J Thorac Cardiovasc Surg. 1986;91:123-32.

4. Kurosawa H, Morita K, Yamagishi M, Shimizu S, Becker AE, Anderson RH. Conotruncal repair for tetralogy of Fallot: midterm results. J Thorac Cardiovasc Surg. 1998;115:351-60.

5. Yamagishi M, Kurosawa H. Outflow reconstruction of tetralogy of Fallot using a Gore-Tex valve. Ann Thorac Surg. 1993;46:1090-3.

6. Kurosawa H, Imai Y, Takanashi Y, Hoshino S, Sawatari K, Kawada M, et al. Infundibular septum and coronary anatomy in Jatene operation. J Thorac Cardiovasc Surg. 1986;91:572-83.

7. Van Praagh R, Durnin RE, Jockin H, Wagner HR, Korns M, Garabedian H, et al. Anatomically corrected malposition of the great arteries $\{$ S,D,L $\}$. Circulation. 1975;51:20-31.
8. Dalvi B, Sharma S. Anatomically corrected malposition: report of six cases. Am Heart J. 1993;126:1229-32.

9. Kirklin JW, Pacifico AD, Bargeron LM, Soto B. Cardiac repair in anatomically corrected malposition of the great arteries. Circulation. 1973;48:153-9.

10. Tsuchida K, Fujiwara T, Ishihara S, Kurosawa H, Imai Y. Intracardiac repair in anatomocally corrected malposition of the great arteries (SDL): report on 2 successful repair. Jpn J Thorac Surg. 1988;37:760-5.

11. Colli AM, de Leval M, Somerville J. Anatomically corrected malposition of the great arteries: diagnostic difficulties and surgical repair of associated lesions. Am J Cardiol. 1985;55:1367-72.

12. Lincoln C, Anderson RH, Shinebourne EA, English TAH, Wilkinson JL. Double outlet right ventricle with 1-malposition of the aorta. $\mathrm{Br}$ Heart J. 1975;37:453-63.

13. Goor DA, Edward JE. The spectrum of transposition of the great arteries with specific reference to developmental anatomy of the conus. Circulation. 1973;48:406-15.

14. Kaneko Y, Murakami A, Imanaka K, Okabe H, Takamoto S. Transannular patch repair of double-outlet right ventricle, $\{S, D, L\}$, and single right coronary artery. J Thorac Cardiovasc Surg. 1999; 117:622-3.

\section{Availability of Journal back issues}

As a service to our subscribers, copies of back issues of The Journal of Thoracic and Cardiovascular Surgery for the preceding 5 years are maintained and are available for purchase from Mosby until inventory is depleted. Please write to Mosby, Subscription Customer Service, 6277 Sea Harbor Dr, Orlando, FL 32877, or call 800-654-2452 or 407-345-4000 for information on availability of particular issues and prices. If unavailable from the publisher, photocopies of complete issues may be purchased from Bell \& Howell Information and Learning, $300 \mathrm{~N}$ Zeeb Rd, Ann Arbor, MI 48106-1346; 734-761-4700 or 800-521-0600. 